e-makâlât Mezhep Araştırmaları, VII/2 (Güz 2014), ss. 117-128.

ISSN 1309-5803 | www.emakalat.com

\title{
MÜSLÜMAN YOGA YORUMCULARI
}

\author{
Carl W. ERNST*
}

Çev. Mehmet ATALAY**

\begin{abstract}
Öz
$\mathrm{Bu}$ makale, Müslüman yazarlarca yoga ile ilgili yazılı mahsul üretme geleneği kapsaminda önde gelen akımlar1 tanitmaktadir. $\mathrm{Bu}$ gaye hedefinde makale, bayan yogiler ve nefes kontrolü (the Kamru Pancasika) konusu üzerine yazılmış en eski Farsça metni ele almakta ve Arapça, Türkçe, Farsça ve Urduca lisanlarında Bengisu Havuzu (The Pool of Nectar) [Amritakunda] olarak bilinen metnin farklı nüshalarını tanitmaktadır. Ayrica makalede, Bengisu Havuzu'nun Muhammed Ğavs tarafindan Bahru'l-Hayat (Hayat Denizi) başlığıyla Farsçaya tercüme edilen nüshasina, yoga pozisyonlarına ilişkin önemli minyatür resimler ihtiva etmesi dolayısıyla özel önem verilmektedir..
\end{abstract}

Anahtar kelimeler: Yoga, Tasavvuf, Amritakunda, Bahru'l-Hayat, Moğol minyatürleri.

\section{Abstract \\ Muslim Interpreters of Yoga}

This article describes the principal currents in the tradition of writings on yoga by Muslim authors, starting with the earliest Persian text on yoginis and breath control (the Kamru Pancasika) and then delineating the different versions of the text known as The Pool of Nectar (Amrtakunda) in Arabic, Turkish, Persian, and Urdu. Particular attention is paid to the Persian version of The Pool of Nectar, translated by Muhammad Ghawth Gwaliyari under the title Bahr alhayat or The Ocean of Life, because of the importance of its miniature illustrations of yogic postures.

Keywords: Yoga, Sufism, Amrtakunda, Pool of Nectar, Mughal miniatures.

* Prof. Dr. Carl W. Ernst, University of North Carolina'da (Chapel Hill) Din Bilimleri (Religious Studies) Bölümünde öğretim üyesi olarak çalışmaktadır. (E-mail: cernst@email.unc.edu). Makalenin -kitap içi bölüm olarak- ilk yayımlandığı yer itibarıly künyesi şöyledir: Carl W. Ernst, "Muslim Interpreters of Yoga," in Yoga: The Art of Transformation, ed. Debra Diamond, (Washington, DC: Smithsonian Books, 2013), pp. 59-68.

** Doç. Dr. Mehmet Atalay, İstanbul Üniversitesi İlahiyat Fakültesi Felsefe ve Din Bilimleri Bölümü Din Psikolojisi Anabilim Dalı'nda öğretim üyesi olarak çalışmaktadır. (E-mail: matalay@istanbul.edu.tr). Bu makale, Prof. Carl W. Ernst'ün özel izniyle -ve kendi son yazdığı taslak esas alınarak- tercüme edilmiştir. 
Şüphesiz ki yoga, günümüzde olağanüstü düzeyde popüler bir olgudur. Belki de yoga, küresel spiritüalite pazarında yer bulmuş en başarılı Hint 'ithali'dir. Dini irtibatları açısından yoga, Hindu ve Budi (Budist) gelenekleri kapsamında zikredilmektedir ama günümüzde aynı zamanda spiritüel ya da fiziksel pratiğin genel ve müstakil şekli olarak da takdim edilmektedir. Yakın geçmişte çağdaş kimlik siyasetinin oynadığı rol dolayısıyla, yoganın herhangi bir şekilde İslam ile bağlantılandırıldığını gören çokları hayli şaşıracaktır. Ne ki, Müslümanların yogayla ilgilenmelerinin uzun ve girift bir tarihi söz konusudur. Bu ilginin tarihi, bin yıl geriye, meşhur âlim el-Bîrûnî̀ye (vef. 1048) kadar gitmektedir. El-Bîrûnî Hint bilimleri ve kültürü üzerine esaslı bir Arapça kitap yazmakla kalmamış, aynı zamanda, Patañjali'nin Yoga Sutra'larının bir nüshasını da Arapçaya tercüme etmiştir. ${ }^{1}$

Yüzyıllar boyunca diğer Müslüman simalar, uzun süren bir kültürler-arası etkileşim geleneğinin parçası olarak Hindistan'da bulunan felsefi ve mistik öğretileri anlama çabasında el-Bîrûnî'yi takip etmişlerdir. Bu kültürler-arası etkileşim, çok miktarda Hint metninin Farsçaya tercüme edilmesi sonucunu doğurmuştur. Bu arada belirtmek gerekir ki, zikredilen dönem itibarıla Farsça; Orta Doğu, Orta Asya ve Güney Asya'nın çoğu bölgelerinde devlet ve kültür lisanı (lingua franca) konumundayd1. Sanat, bilim, siyaset ve metafiziğe kadar birçok konuyu kapsayan ve yaklaşık olarak sekiz yüzyıl süren bu tercüme hareketi, önem ve kapsam itibarıla, Yunan felsefe ve biliminin Arapçaya ya da Budî metinlerin Sanskritçeden Çince ve Tibet lisanına tercüme edilmesi ile mukayese edilebilir nitelikte bulunmaktadir. ${ }^{2}$

1 Bruce B. Lawrence, "Bīrūn̄̄, Abū Rayhān. viii. Indology," Encyclopaedia Iranica, vol. 4 (1990), pp. 285-287 (http://www.iranicaonline.org/articles/biruni-abu-rayhan-viii).

2 Carl W. Ernst, "Muslim Studies of Hinduism? A Reconsideration of Persian and Arabic Translations from Sanskrit," Iranian Studies 36 (2003), pp. 17395. Burada zikredilen bütün makalelerime internet üzerinden erişilebilmektedir: (http://www.unc.edu/ cernst/articles.htm). Hindistan ile ilgili olarak gün yüzüne çıkmış Farsça literatür bilgisi için Fars-Hint projesine (the Perso-Indica project) bkz.: (http://perso-indica.net). 
Hint kültürüne yönelik bu geniş ölçekli ilginin yanında, yogiler (ya da Kuzey Hindistan telaffuzuyla, cogiler) olarak bilinen Hint münzevilerinin ve mistik üstatlarının tefekkür (meditasyon) uygulamaları ve batıni güçlerine ilişkin olarak daha özel bir ilgi sözkonusuydu. Önemli ölçekte bu ilgi, son derece pratik bir nitelik arz etmekteydi. Ayrıca, saray vakayinamelerinden ve seyyah kayıtlarından açıkça anlaşılmaktadır ki yogilerin olağanüstü faaliyetleri birçok Müslümanı etkilemiş bulunmaktayd1. ${ }^{3} \mathrm{Bu}$ etkilenme durumu; tıpkı diğer krallar gibi, kendilerine üstünlük sağlayacak -astroloji, büyü ya da tıp gibi- herhangi bir özel bilgi ya da güç temin etme konusunda daima heveskâr olan Müslüman hükümdarlar örneğinde özellikle tebarüz etmektedir. Nitekim Kuzey Afrikalı seyyah İbn Battûta'nın gözlemleyip kaydettiğine göre, 14'üncü yüzyılda Delhi'de Sultan Muhammed İbn Tuğluk, havada yükselebilme becerisini başarıyla sergileyen bir yogi ile konuşmusstur. Yogilerin hayret uyandıran maharetleriyle ilgili anlatıların popüler Hindistan literatürünü önemli ölçüde istila etmiş olması dolayısıyla Güney Asya Müslümanlarının bu maharetlere aşina olduğunu ve bu maharetlere ilişkin daha geniş ölçekli bir hâkimiyet temin etmeye çalıştığını öğrenmek şaşırtıcı değildir. Müslümanların yogaya ilgisinin, felsefi bilgi arayışından spiritüel uygulamalar ihraz etmeye ya da sadece batıni bilgi arzusuna kadar geniş bir motivasyon tabanının olduğu söylemek makul bir yaklaşım olarak tezahür etmektedir. Hint münzevileri Müslüman fakir ya da derviş modeli içinde erimiştir. Bu münzeviler; resimli Moğol tarihçelerinde, Sanskritçe metinlerin Farsça tercümelerinde ve sadece resimlerden müteşekkil albümkitaplarda sıklıkla Müslüman fakir ya da derviş şeklinde tezahür etmektedir.

Felsefi perspektif itibarıla Hint dinlerini anlamaya ilişkin ana çerçeve, Farslı düşünür Sühreverdî (vef. 1191) tarafından geliştirilen ve yaygin olarak İşrâkîlik (Illuminationism) olarak bilinen bir Neo-Platonik düşünceydi. Bu düşünceye göre evrenin ilahi kayna-

3 Carl W. Ernst, "Accounts of Yogis in Arabic and Persian Historical and Travel Texts," Jerusalem Studies in Arabic and Islam 33 (2008), pp. 409-426. 
ğından sudûr eden varlık dereceleri, şu ya da bu yoğunlukta 1 ş1k tezahürleri olarak tanımlanmaktadır. Aynı zamanda, iki önemli İslam filozofu olarak Farabi ve İbn Sina tarafından geliştirilen nübüvvet nazariyesine göre dinler, felsefi gerçeklerin -eğitimsiz insan kitlelerinin anlayabileceği şekilde düzenlenmiş- simgesel açıklamaları olarak değerlendirilmekteydi. Bu yaklaşım esas alındığında, yogik ya da Vedantik öğretilerin, felsefenin yerel geleneklere uyarlanışının bir başka örneği olarak görülmesi hiç de zor değildi. Moğol Hindistan'inda İşrâkî felsefenin revaç bulduğuna dair birkaç yazılı mahsul sözkonusudur. $\mathrm{Bu}$ yazılı mahsullerin bazıları doğrudan doğruya Hint dini düşünce ve uygulamalarına yoğunlaşmaktadır. ${ }^{4} \mathrm{Bu}$ bağlamda dikkat çekici bir örnek, Vedanta üzerine yazılmış ve şair Feyzîye isnad edilen Farsça bir risale olarak Marifet Aydınlatıcısı (Şerîku'l-Marifet ya da The Illuminator of Gnosis) başlıklı çalışmadır. $\mathrm{Bu}$ risale, Krişna'nın ilahi hakikatin tecellisi olduğunu izah etmek amaciyla Yunan ve Hint irfanını (wisdom) birbiriyle irtibatlandırmaktadir. ${ }^{5}$

Tasavvuf ya da İslam mistisizmi açısından da yoga, keşif çabalarına değecek bir konuydu. Aslında bu iki gelenek, mukayeseli mistisizm çalışmaları kapsamında çoğu kez birlikte değerlendirilmiştir. Çoğu âlim ve araştırmacı da tasavvufun şu ya da bu şekilde yogadan istintaç edilmiş olması gerektiğini düşünmektedir. İlk dönem oryantalistlerince gündeme getirilip teşvik edilen bu nazariye, bu oryantalistlerin 'bütün Doğulu öğretilerin en nihayet aynı şey olduğu' şeklindeki köklü kanaatlerine dayandığı gibi, aynı zamanda, 'İslam'ın spiritüalite ile bağdaşmayan sert ve salt kanuni-fikhi bir din olduğu' şeklindeki aksiyomatik varsayımlarının 1 şı̆̆ altında hayatiyet kazanmıştı. Aslında, tasavvufun bir şekilde Hint kaynaklarından neşet ettiği yönünde ikna edici ve tarihsel gerçeklere dayalı bir argüman geliştirmek imkânsızdır; İslami mistisizm (yani tasav-

4 Carl W. Ernst, "The Limits of Universalism in Islamic Thought: The Case of Indian Religions," Muslim World 101 (January 2011), pp. 1-19.

5 Carl W. Ernst, "Fayzi's Illuminationist Interpretation of Vedanta: The Shariq al-Ma rifa," Comparative Studies of South Asia, Africa and the Middle East 30/3 (2010), pp. 156-64. 
vuf) gerçekten İslamidir ve 11'inci ve 12'nci yüzyıllarda Hindistan'a varmazdan evvel esas itibarıyla Bağdat ve Horasan'da teşekkül etmiştir. ${ }^{6}$ Ne ki ilginç bir tesadüf eseri olarak, sufilerin gelmesiyle birlikte Hindistan'da yeni 'zahit' (ascetic) hareketlerin tezahür etmesi sözkonusuydu. Bu yeni 'zahit' hareketleri, 'hatha yoga' denen yoga türünü uygulamakla birlikte Hint dinleri sahnesinde çok önemli yeni roller üstlenen Nath ya da Kanphata yogilerini de içermekteydi. Bu yogiler 'ritüel ölüm' tecrübe ettiklerinden ve Hinduizmin üst s1nıfının safiyet kısıtlamalarına maruz olmadıklarından dolayı, çoğunlukla sufi üstatlarca nezaret edilen Hindistan'daki hankâhların açık mutfaklarına serbestçe girebiliyorlardı. Bundan dolayıdır ki erken bir tarihten beri Hint sufilerinin yazılı mahsullerinde yoga üzerine sayısız konuşma ve düşünce örneklerine malik bulunmaktayız. Bazen bu örnekler, nefes kontrolünün meditasyona yardımcı ilave bir unsur olduğu yönündeki müşahedeyle sınırlı olmaktadır. Fakat genel olarak bu örneklerden bariz bir şekilde ortaya çıkmaktadır ki sufiler, tasavvufi meditasyon sürecinde dikkate alınan letâif (latîfeler) olgusuna ve Allah'ın diğer (Arapça) isimlerinden müteşekkil zikir formüllerine -tartışmaya açık olsa da- hayli benzeyen nazik çakra fizyolojisi ve mantraların kuvvet boyutlarını ihtiva eden daha girift yoga öğretilerine yakın ilgi göstermişlerdir. Gerçekten de, en önemli mutasavvıflardan biri olarak Hindistan'daki Çeştî tarikatının kurucusu Muineddin Çeştî̀ye (vef. 1236), yoga ve meditasyon üzerine yazılmış ve çok geniş tedavül kazanmış -ve diğer başlıkları yanında Insan Üzerine Risale (Treatise on the Human Being) ya da Yoganin Doğası Üzerine Risale (Treatise on the Nature of Yoga) diye bilinenbir metnin isnat edildiği görülmektedir. Bu metnin yazarının kim olduğu ile ilgili olarak bazı sorunlar sözkonusudur, çünkü nüshalarının hiçbiri on yedinci yüzyıldan daha eski değildir. Ayrıca, halefleri tarafından Muineddin'in hiçbir kitap yazmadığı ileri sürülmüştür. $\mathrm{Ne}$ ki, bu çalışmanın tasavvufi çevrelerde revaç bulması ve Hint tasavvufunun kurucu simalarından birinin yüksek manevi tecrübe-

6 Ahmet T. Karamustafa, Sufism: The Formative Period (Berkeley: University of California Press, 2007); Carl W. Ernst, "Situating Sufism and Yoga," Journal of the Royal Asiatic Society, Series 3, 15:1 (2005), pp. 15-43. 
leriyle irtibatlandırılması, yoganın bazı açılardan tasavvuf ile özünde bağdaşır ya da en azından böyle değerlendirilebilir olduğu yaklaşımını takviye etmektedir. ${ }^{7}$

Yoga konusuna hasredilmiş ilk temel Farsça kaynak, 14'üncü yüzyılda, bilinmeyen (anonim) bir yazar tarafından, Hintçe bir başl1k olarak Kamru Bijaksa (The Kamarupa Seed Syllables [Kamarupa Çekirdeği Heceleri) başlığıyla tedvin edilmiştir. Bu başlık, geleneksel olarak tılsım ve olağanüstü olayların kaynağ1 addedilen (ve Hindistan'ın kuzey doğusundaki Assam bölgesinin bir diğer adı olan) Kamarupa'ya göndermede bulunmaktadır. Sözkonusu başlık, aynı zamanda, 'çekirdek (bija) mantraları' olarak bilinen ilk en eski (primordial) hecelere telmihte bulunmaktadır. Bu metnin yazıldığ ve geniş tedavül kazandığı tarih, Şiraz'da Şerefuddin Amûlî (vef. 1353) tarafından tedvin edilen önemli bir Farsça ansiklopedide yer alan iktibaslara dayanılarak tesbit edilmektedir. Ansiklopedinin tabii ilimler bölümünde yer alan bu iktibaslar, geleceği tahmin etme hedefinde nefes kontrolü uygulaması ile çakralara ilişkin meditasyon uygulamalarını ele almaktadır. ${ }^{8}$ İyi talih eseri olarak İtalyan seyyah Pietro della Valle, 1622 yılında İran'ın güney doğu bölgelerinde seyahat ederken bu metnin noksansız bir nüshasını temin etmiştir (bu nüsha şimdi Vatikan Kütüphanesinde muhafaza edilmektedir). İtalyan seyyahın bu nüshayı İran coğrafyasında yaşayan bir grup entelektüelden temin etmiş olması gerçeği, bu metnin Hindistan dışında hâlâ revaçta olduğunu göstermektedir. Nefes kontrolü ve çakra meditasyonlarıyla alakalı bilgilere ilave olarak bu noksansız metin, 'yogini' (bayan yogi) olarak bilinen -ve mütercimin "manevi varlık" (spiritual being [rûhâniyyât]) tabir ettiği- 64 ilahi varlığı (de-

7 Carl W. Ernst, "Two Versions of a Persian Text on Yoga and Cosmology, Attributed to Shaykh Mu in al-Din Chishti," Elixir 2 (2006), pp. 69-76, 1245. Bu çalışmanın Scott Kugle tarafından gözden geçirilip tadil edilmiş şekli için bkz.: Scott Kugle (ed.), Sufi Meditation and Contemplation: Timeless Wisdom from Mughal India (New Lebanon, NY: Suluk Press/Omega Publications, 2012), pp. 167-92.

8 Carl W. Ernst, "A Fourteenth-Century Persian Account of Breath Control and Meditation," in Yoga in Practice, ed. David Gordon White, (Princeton: Princeton University Press, 2011), pp. 133-39. 
ity) 'celbetmeye' ilişkin ayrıntılı uygulamalardan söz etmektedir. Ayrıca, bu bağlamda, Kamak Devi (Sankstritçesi: Kamahya) olarak bilinen dişi ilahi varlığa özel önem verilmektedir. Bununla beraber belirtilmeli ki, sözkonusu dişi ilahi varlığın (Kamak Devi: Kamahya) bu metindeki tasviri, günümüz Assam'ındaki türbesine izafe edilen 'tantrik' (ilahi) sıfatlardan önemli ölçüde farklılık arz etmektedir. Yoga fizyolojisi geleneği belli ölçüde sözkonusu metinde sergilenirken asıl temel ilgi, güçlü mantralar aracılığıyla -yoga uygulayıcısına arzusunu kazandırabilecek- yogini'leri celbetmek suretiyle elde edilecek faydaya yoğunlaşmaktadır. Mütercim bu bilgileri Hinduların en meşhur kitabından temin ettiğini iddia etmektedir. Oysaki bu metnin herhangi bir Hint lisanında hayatiyet sürdüğüne dair hiçbir emare sözkonusu değildir. Ayrıca mütercim, şifahi öğreti olduğu anlaşılan bilgilere itibar kazandırmak amacıyla, İslam âlimlerinin kendi yazılı mahsullerinde sergilediği dili ve üslubu (ve İslamileştirme amacına yönelik diğer 'tadil hamleleri'ni) istihdam etmektedir. $\mathrm{Bu}$ uygulamaları tasvir etmek amaciyla mütercimin kullandığ anahtar terimler, 'vehm' ('büyülü hayal') ve 'riyâzet'dir ('zühdî disiplin'). İkinci terim (riyâzet), yoganın normal Farsça mukabilidir (cog). ${ }^{9}$ Della Valle, bu metinde tasvir edilen uygulamaları kısmi bir başaryyla denediğini iddia etmiş ve aynı metni İtalyancaya tercüme etme niyetini dile getirmiştir. Ancak, öyle görünmektedir ki Della Valle, bu tercüme işlemini hiç gerçekleştirmemiştir.

Fakat yogaya ilişkin olmak üzere diğerlerinden açık ara farkla en önemli çalışma, Müslüman bir yazar tarafından kaleme alınmış ve birkaç değişik başl1kla bilinen Arapça bir metindir: Beşeri Dünyayı Anlamak için Anlamların Aynası (The Mirror of Meanings for the Comprehension of the Human World); Tek Başina Uygulanabilir Tip (Do-It-Yourself Medicine); ve en önemlisi olmak üzere, Hayat Suyu Havuzu (The Pool of the Water of Life [Havzu Mâi'l-Hayat]. Bu son başl1k da çoğu kez Havzu'l-Hayat ya da Hayat Havuzu (Pool of Life)

9 Carl W. Ernst, "Being Careful with the Goddess: Yoginis in Persian and Arabic Texts," in Performing Ecstasy: The Poetics and Politics of Religion in India, ed. Pallabi Chakrabarty \& Scott Kugle, (Delhi: Manohar, 2009), pp. 189-203. 
diye kısaltılmaktadır. Adı bilinmeyen (anonim) bir yazar tarafından kaleme alınmış bu popüler metin, 1212 yılında Türk ordularının Bengal'in doğu bölgelerini fethettiği zamana tekabül eden tercüme hareketi sürecinde gün yüzüne çıktığını iddia etmektedir. Her ne kadar sözkonusu orijinal metnin tercümesi olduğuna dair bir belirti sözkonusu değilse de, anlaşılan o ki bu metin, Amritakunda (Bengisu Havuzu [The Pool of Nectar]) olarak bilinen Sanskritçe meşhur bir çalışmanın tercümesidir. Baş tarafında zikredilen hikâyeye göre, Semerkand'lı bir Müslüman kelamcı (teolog), Assam'lı bir yogi ile başarılı bir münazara yapmıştır. Münazarada mağlup olan yogi, İslam dinine ihtida etmiş ve bir minnet eseri olmak üzere bu fevkalade kitabın yani Amritakunda'nın bir kopyasını çıkarmıştır. İslam dinine ihtida etmiş bir başka yoginin yardımıyla bu kitap en nihayet Arapçaya tercüme edilmiştir (yogilerin İslam dinine ihtida ettiğine dair böylesi hikâyeler, sufi menâkıbnâmelerinde sıklıkla rastlanan temalardır). Bu hikâye neredeyse kesin olarak kurmacadır, çünkü yogi ile (Hindistan'a hiç gitmemiş malum bir sima olarak) kelamc1 arasındaki tartışma, Medine Yahudileriyle Hz. Peygamber arasındaki münazaraların örneklendirdiği modeller esas alınarak serdedilmiştir. Dahası bu anlatıyı, iki Orta Doğu kaynağından alınmış ilave 'anlatı yapiları' (modeller) takip etmektedir: birincisi, ruhun maddeye nüzul etmesine ilişkin olarak irfanî (gnostic) "Kaside-i Bürde"den alınma meşhur mesel; ikincisiyse, dâhili ve hârici duygu ve duyumlara ilişkin olmak üzere İşrakî filozof Sühreverdî'nin en önemli yazılı mahsullerinden birinden alınma ayrıntılı bir mecazi tasvir. Bütün bunlar, takip eden on bölüm içinde değerlendirilen yoga uygulamalarına ilişkin bir mukaddime işlevi görmektedir. Sözkonusu bölümler; ayrıca, yoga duruşlarına dair resimler ihtiva ettiği gibi, mahir bir fizyolojik kontrolün nasıl olması gerektiğine, büyük ve küçük evrene (insan), mantralara, ölüm zamanını tahmine, çakralara, bayan yogilere ve meditasyon tarzlarına ilişkin değerlendirmeler ihtiva etmektedir. Büyük ihtimalle yazar, Hindistan dinlerini anlamak amacıyla Farsça yazılmış felsefi öğretilerden istifade etmiş bir 16'nc1 yüzyıl entelektüelidir. Bu yazarın, konu üzerinde en iyi ve en eski Arapça yazma metnin (1699) önsözünde bizzat zikredilmiş ve daha önceleri gün yüzüne çıkmış Farsça Kamru Bijaksa'ya aşina olduğu- 
na dair kanitlar da sözkonusudur. ${ }^{10} \mathrm{Bu}$ yazarın tercüme yönteminin, gerek mantraları Allah'ın diğer Arapça adlarına (esmâ-i hüsnâ) eşitlemek gerekse de yogileri ve (diğer) ilahi varlıkları İslam peygamberlerine eşitlemek yoluyla yoga kavramlarını İslami karşılıklarına "tercüme" etmek olduğu anlaşılmaktadır.

Havzu'l-Hayat'in (The Pool of Nectar) daha sonraki tarihi, girift ve karmaşıktır. Arapça nüshaya ilişkin olmak üzere -biri daha çok Hint unsuru ihtiva eden diğeriyse fark edilebilir ölçüde İslamileştirme çabası gösteren- iki tahkikli nüsha mevcuttur. 19'uncu yüzy1lın sonlarına doğru Arapça metin, iki defa Osmanlı Türkçesine tercüme edilmiş ve İstanbul'daki Mevlevi tarikatı çevrelerinde revaç bulmuştur. Bu metnin bazı nüshaları sadece 'Hint tılsımı' diye tasnif edilmesine rağmen İstanbul kütüphanelerindeki birçok yazma nüsha yanlışlıkla Endülüslü meşhur tasavvuf üstadı İbn Arabi'ye (vef. 1240) isnat edilmektedir. Günümüzde, Suriye'nin Şam şehrinde yaşayan ve İbn Arabi tarafından kaleme alınmış bir yazılı mahsul olduğu zannıyla bu metinde gündeme getirilen uygulamaları tedris eden bir tasavvuf şeyhi mevcuttur.

$\mathrm{Bu}$ öğretilerin intikali bağlamında ikinci büyük adım, 16. yüzyıl Hindistan'ında ortaya çıkmıştır. Bu dönemde, Şettârî tarikatının tanınmış şeyhi Muhammed Gavs [Muhammad Ghawth Gwaliyari] (vef. 1563), Bengisu Havuzu'nun (The Pool of Nectar) Arapça nüshasını Bahru'l-Hayat (The Ocean of Life) başlığı ile Farsçaya tercüme etmiştir. ${ }^{11} \mathrm{Bu}$ tercüme, muhtemelen o dönemde yaşayan yogilerin verdiği şifahi bilgilerden istifadeyle Arapça nüshanın genişletilmiş ve tadil edilmiş şekli olarak gün yüzüne çıkmıştır. Ayrıca, bu Farsça

10 Carl W. Ernst, "Fragmentary Versions of the Apocryphal 'Hymn of the Pearl' in Arabic, Turkish, Persian, and Urdu," Jerusalem Studies in Arabic and Islam, 32 (2006), pp. 144-188; Carl Ernst, "The Islamization of Yoga in the Amrtakunda Translations," Journal of the Royal Asiatic Society, Series 3, 13:2 (2003), pp. 199-226. Arapça metinlerin hiçbiri 17'nci yüzyıldan daha eski değildir.

11 Carl W. Ernst, "Sufism and Yoga according to Muhammad Ghawth," Sufi 29 (Spring 1996), pp. 9-13; Nazir Ahmad, "The Earliest Known Persian Work on Hindu Philosophy and Hindu Religion," in Islamic Heritage in South Asian Subcontinent (Vol. I), ed. Nazir Ahmad \& I. H. Siddiqui, (Jaipur: Publication Scheme, 1998), pp. 1-18. 
tercümede, hali hazırda elimizde bulunandan daha eski bir Arapça nüshadan istifade edildiğine dair belirtiler de sözkonusudur. $\mathrm{Bu}$ bağlamda, ansiklopedik anlamda tanıtıcı bir not olarak şu önemli bilgiyi de eklemek gerekir: Farsça tercüme metnin birkaç nüshasında, yoga uygulama pozisyonlarını resmeden 21 adet minyatür resim mevcuttur (bir mukayese yaparsak, resimlerin bulunduğu bölüm Farsça tercümede, Arapça orijinal nüshanın -sadece dört pozisyona yer veren- resim bölümünden dört kat daha uzun ve hacimlidir). ${ }^{12}$ 19'uncu yüzyılın ortalarında bu Farsça metnin kısmi bir DakaniUrduca tercümesi, Adoni-Urduca olarak da istinsah edilmiştir.

Bahru'l-Hayat'ın yoga resimlerini içeren dördüncü bölümünün altı farklı nüsha üzerinden dikkatli bir tetkiki, bazı yeni gözlemlere yol açmaktadır. ${ }^{13} \mathrm{Bu}$ nüshalarda bazı önemli kelime farkl1lıkları hatta eksiklikleri sözkonusudur. Öte yandan tesbit edilebilmektedir ki, Chester Beatty nüshasinda 22'nci formadan sonraki forma tamamen kayıptır. Bu eksikliğin, sözkonusu metnin daha önce söylendiği gibi 21 tane değil de aslında 22 tane yoga pozisyonu tasvir ettiği gerçeğini örttüğü anlaşılmaktadır. Bu durum da, orijinal nüshada (mevcut resimlerde keza yer almayan bodhak pozisyonu için) bir başka tasvir olabileceği ihtimalini gündeme getirmektedir. Ayrıca belirtmek gerekirse, metinde resmedilen bedeni pozisyonlar için asana terimini kullanmak isabetsiz görünmektedir, çünkü bu terim (ya da bu terimin Farsça mukabili) metinde yer almamaktadır. Aksine bu uygulamalar, ardarda zikredilerek bir araya getirilmiş iki kelimeyle tanıtılmaktadır: Hintçe şebde (shabda) ("kelime") kelimesi ile Arapça-Farsça zikr ("hatırlama") kelimesi. Bu kelimeler, her ne

12 Resimli nüshaların en eskisi, bu kitap içinde [Debra Diamond (ed.), Yoga: The Art of Transformation (Washington, DC: Smithsonian Books, 2013)] tanıtıldığı gibi Chester Beatty nüshasıdır. Aşikâr biçimde aynı resim düzenini izleyen diğer üç nüsha, şuralarda bulunabilmektedir: (1) The University of North Carolina at Chapel Hill, Rare Book Collection (tarih: 1718); (2) the Salar Jung Museum, Hyderabad (Madhahib Farsi 1, tarih: 1815); ve (3) Söylentilerin doğru olduğunu kabul edersek, mütefevvâ Simon Digby'nin kütüphanesinde.

13 Müracaat ettiğim nüshalar şunlardır: India Office, Ethé 2002; Ganj Bakhsh 6298, Islamabad; Chester Beatty; Liyaqat Memorial Library 46, Karachi; British Library Or. 12188; ve India Office, Ashburner 197. 
kadar bedeni pozisyonlarla alakalı ayrıntılı değerlendirmeler sözkonusuysa da, sözkonusu yoga uygulamalarında kesin olarak anahtar unsur addedilen mantra ifadelerine delalet etmektedir. Dahas1, zor teknik terimlerin müstensih tarafindan uyarlanması (transkripsiyon) açısından kuvvetle tahmin edilebileceği gibi, sözkonusu nüshalarda bu uygulamaların adları bağlamında önemli varyasyon farklar1 mevcuttur. Farklilıkların Devanagari hattında (bu nüsha şurada bulunmaktadir: India Office Ethé 2002) hece hece kaydedilen terimler yardımıyla ara sıra açıklığa kavuşturulabildiği yerlerde bile Bahru'l-Hayat'daki pozisyon adları, 'hatha yoga' üzerine daha sonra yazılmıs Sanskritçe metinlerdeki aynı yoga pozisyonlarının adlarından sık sık ve önemli ölçüde farklılık göstermektedir. Yanısıra, Farsça tanımlamalar, ekseriya -başka türlü bulunamayacak türden- ayrıntılar vermektedir. Diğer bir deyimle, Bahru'l-Hayat'in metni, yoga uygulamaları ve terminolojisiyle alakalı olmak üzere değerli bir tarihsel belge teşkil ettiği gibi, aynı zamanda, Sanskrit dili ve kültüründeki yoga geleneğine önemli bir 'tamamlayıcı ilave'ye tekabül etmektedir.

Yoga uygulamalarını belgeleyen ve ayrıca yogayı resimlerle tan1tan son temel Farsça kaynaklar, Müslüman yazarlar tarafindan değil de, önce Moğol İmparatorluğu idaresi bünyesinde sonra da İngiliz müstemleke idaresinde çalışan Hindu kâtipler (münşîler) tarafından yazılmıştır. Dönemin İslami ve Farisi kültürünün yoğun etkisi altındaki bu Hindu âlimler; hem İmparatorluğun eyaletlerinin gelir istatistiklerini kaydetmek hem de Hint dini topluluklarının âdet ve inançlarına ilişkin bilgiler serdetmek suretiyle, Moğol veziri Ebu'l-Fazl'n kaleme aldığ1 Â'în-i Ekberî (آئين اكبرى) [ya da Ekber Kanunu] tarzında telif edilmiş coğrafya sözlüklerine katkıda bulunmuşlardır. 18'inci yüzyıl ortalarından kabaca 1830 y1lına kadar müstemleke idaresinin kullandığı dilin Farsça olduğu dönem itibarıyla İngiliz görevliler, Hindistan dinleriyle alakalı olmak üzere Farsça risaleler yazmaları amacıyla çok sayıda Hindu âlimlerden müteşekkil heyetler teşkil etmişlerdi. Anglo-Fars diye nitelendirebileceğimiz bu telif ve derleme eserlerin birkaç tanesi, grup halinde yogilere ve grup halinde münzevilere ait resimler de içermekteydi. Ayr1ca bu resimler, bir anlamda, sözkonusu dini grupların kimliğine 
dair bir saha tetkiki kılavuzu işlevindeydi. Bu bağlamda iki dikkat çekici örnek, 1800 yılında Sital Singh tarafından tedvin edilen Yogilerin Silsilesi (The Chain of Yogis ya da Silsile-i Cûgiyân) başlıklı kitap ile Mathuranath adında bir Brahmin tarafından yazılan ve John Glyn adlı biri tarafından Hindistan'ın Benares ssehrindeki dinlere dair bir k1lavuz metin olarak 1812 yllında tab edilen Dinlerin Bahçesi (The Gardens of Religions ya da Riyâzu'l-Mezâhib) başlıklı kitaptır. Yogileri tasvir eden bu kitapların tarihçesi ve türüne dair çalışmalar henüz gün yüzüne çıkmayı beklemektedir. Ancak, bu geç dönem Farsça metinlerin Hint dinlerine ilişkin Moğol yaklaşımı ile nüfus sayımı kayıtları, mahkeme defterleri ve oryantalistlerin araştırmalarına dayandırılan müstemleke dönemi din kategorileri arasında bir köprü işlevi gördüğünü söylemek gayet tabii ve makul görünmektedir. ${ }^{14}$

Müslümanların yoga felsefesi ve uygulamasına yönelik ilgilerinin uzun tarihi, günümüzde -dini uygulamanın gerçek tarihi ve sosyolojisini dikkate almaksızın ekseriya sadece ilgili dini metinlerin kendi terimleriyle tanımlanan- din olgusunu anlama çabası sürecine çoğu kez taşıdığımız at gözlüğü siperlerini bertaraf etmeye yardımcı mahiyette olmaktadır. İslam ile Hinduizm arasında milliyetçi gündemlerce özellikle ve kuvvetle vurgulanan mevcut ideolojik karşıtlıklar, dini alan itibarıyla yüzyıllar boyunca ortaya çıkmış kültürleraras1 etkileşimleri anlama fırsatına hiç imkân bırakmamaktadır. Resimler ve Arapça, Farsça, Türkçe ve Urduca tercümeler yoluyla yoganın kültürler-arası anlamda bir intikal süreci geçirmesi, Hint dinleri tarihinin -yogaya büyük bir ilgi göstermiş Müslüman yorumcular da dâhil olmak üzere- geniş ölçekli bir kaynak bütününü hesaba katması gerektiği yönünde önemli bir hatırlatıcı unsur olmaktadir.

14 Carl W. Ernst, "Anglo-Persian Taxonomies of Indian Religions," "Indian Pluralism and Warren Hastings's Orientalist Regime," başlıklı sempozyumda açılış konuşması, Tregynon, Wales, July 18-20, 2012. 